\title{
The Effect of Output-based Task Repetition on EFL Learners' Speech Act Production
}

Hossein Ahmadi, Islamic Azad University, Science and Research Branch, Tehran, Iran

Farid Ghaemi*, Islamic Azad University, Karaj, Iran

Parviz Birjandi, Islamic Azad University, Science and Research Branch, Tehran, Iran

\begin{abstract}
This study investigated the effects of different output-based task repetition conditions on EFL learners' speech act production. Three intact classes of English-major students constituted three instructional groups: (1) the explicit task-repetition (ETR) group, (2) the implicit task-repetition (ITR) group, and (3) the no-input task repetition (NTR) group. All the three groups engaged in the repetition of outputgeneration tasks. However, before the second performance of the task, the ETR group received input coupled with metapragmatic information, the ITR group received visually enhanced input coupled with a consciousness raising task, and the NTR group received no input. The results of a written discourse completion test (WDCT) revealed statistically significant gains in the learners' performance from the pretest to the posttest in the ETR and ITR groups, but not in the NTR group. Moreover, the analysis of differences across the groups in the posttest revealed the superiority of the ETR over the ITR and NTR groups. The results suggest that output-based task repetition cannot enhance EFL learners' speech act production ability unless learners are provided with input before the second performance of the task. Also when explicit and implicit instructional methods are integrated with output-based task repetition, the explicit approach is more effective than its implicit counterpart.
\end{abstract}

Key words: Output; Metapragmatic information; Visual enhancement; Task repetition; Speech acts

\section{Article Information:}

Received: 12 January 2016

Revised: 2 August 2016

Accepted: 20 August 2016

Corresponding author: Department of English Language, Karaj Branch, Islamic Azad

University, Karaj, Iran_ Email address: ghaemi@kiau.ac.ir 


\section{Introduction}

There have been numerous studies delving into interlanguage pragmatics (ILP) development in the past three decades. According to Rose (2005), these studies fall into three categories dealing with (1) whether a particular area of pragmatics is at all teachable, (2) whether instruction is more effective than simple exposure, and (3) whether there are differential effects for more than one type of instructional intervention. Furthermore, Rose argues that "studies which fall into the third category are likely to yield information that is most relevant for pedagogical purposes" (p. 390). With respect to the third category of ILP research, the majority of the studies have examined the effectiveness of explicit versus implicit methods of ILP instruction (Rose, 2005; Taguchi, 2015). In addition to the interventional studies dealing with explicit versus implicit instruction, the area of ILP has witnessed studies examining the effects of output-based instruction (Jernigan, 2007), input processing instruction (Takimoto, 2009), input-based versus outputbased tasks (Ahmadi, Ghafar Samar, \& Yazdani Moghaddam, 2011), practicebased instruction (S. Li, 2012), task-based language teaching (TBLT) (Tajeddin, Keshavarz, \& Zand-Moghadam, 2012), input-based task repetition (Takimoto, 2012), and task complexity (Kim \& Taguchi, 2015).

An outstanding issue in TBLT is task repetition. As a type of task planning, it is defined as "repetition of the same or slightly altered task - whether the whole tasks, or parts of a task" (Bygate \& Samuda, 2005, p. 43). Task repetition is found to affect EFL learners' performance on a task (Ellis, 2009; Gass, Mackey, Fernandez, \& Alvarez-Torres, 1999; Nemeth \& Kormos, 2001; Sheppard, 2006) and their acquisition of L2 (Ahmadian, 2011). Referring to Sheppard's (2006) findings, Ellis (2009) emphasizes the importance of feedback and input before the second performance of a task. Following this line of research, the present study was designed to examine the effects of output-based task repetition accompanied by input plus metapragmatic information, visually enhanced input plus consciousness raising (CR), and no input on EFL learners' speech act production. 


\section{Review of the Related Literature}

\subsection{Task Repetition}

Repetition has been considered as a vital factor in SLA from various perspectives. Traditionally, the behavioristic view of learning has assigned a basic role to repetition. Through applying the principles of repetition and reinforcement, the practitioners of this view of learning draw on exercises and drills that lead the learner to L2 habit formation (Pica, 2011). Repetition has also been discussed in the light of language learning as cognitive skill acquisition. This view of SLA assumes that repetition enhances automatization (Van den Branden, 2007). With the introduction of task-based language teaching, task repetition received supreme importance in L2 instruction. In this respect, Ellis (2005) conceives of task rehearsal or repetition as a form of task planning and states that it involves performing a task before the main performance "with the first performance of the task viewed as preparation for the subsequent performance" (p. 3).

The effect of task repetition on L2 performance and acquisition has been the focus of a number of studies. Bygate's (1996) study is one of the earliest attempts to investigate task repetition. Bygate asked one language learner to narrate 'Tom and Jerry' cartoon on two occasions with a three-day interval. The participant was not told on the first occasion that the task would be repeated three days later. The results revealed an improvement in complexity, with the learner using more lexical verbs, more regular past tense forms, and a wider range of vocabulary and cohesive devices. Moreover, there were fewer inappropriate lexical collocations and more self-correcting repetitions in the second performance of the task.

Gass et al. (1999) investigated the effects of task repetition on the linguistic output of L2 learners of Spanish. The participants, who were native speakers of English, watched video segments four times and recorded their own on-line rendition in Spanish. There were two experimental groups and one control group. One experimental group watched the same video three times, with an interval of two or three days, and the other experimental group watched different videos each time. At Time 4, one week after the third time, both experimental groups watched a 
new video. The control group watched videos only at Time 1 and Time 4 . The results revealed that task repetition had an effect on the overall proficiency, accuracy in the use of estar (a Spanish copula verb), and lexical sophistication.

Furthermore, Lynch and McLean (2000) found that identical task repetition is useful in improving learners' interlanguage. They used a task called 'poster carousel', in which students were paired up and asked to read a research article and prepare a poster based on it. In this task, each student answered questions about their poster asked by different visitors. Comparing the performance of two participants at markedly different levels of English proficiency, Lynch and Maclean found that both participants benefited from task repletion as operationalized in their study.

As a follow-up to Bygate (1996), Bygate (2001) investigated the effects of repeating an interview task and a narrative task with a ten-week interval on the participants' performance on the same task and a new task of the same type. The participants included 48 learners of English. They were randomly assigned to one of the three groups (i.e., narrative task group, interview task group, and control group). Bygate (2001) found that identical task repetition improved participants' performance in terms of both fluency and complexity.

Moreover, Sheppard (2006) investigated the effects of task repetition accompanied by input or feedback on complexity, accuracy, and fluency. The input and feedback were designed to draw subjects' attention to linguistic forms between the first and second performance of the tasks. The results revealed that task repetition cannot have beneficial impacts on acquisition unless learners are provided with input or feedback on their initial performance of the task.

Finally, Ahmadian (2011) investigated the effect of repeating the same task on the performance of a new task. Thirty intermediate EFL learners from two intact classes were assigned to a control group and an experimental group. The control group only did an oral narrative task and an interview task, which were about six months apart. Participants in the experimental group performed the oral narrative task on eleven occasions, each with an interval of two weeks and then performed 
the interview task at the end of the six-month period. Ahmadian concluded that massed repetitions of the same task can improve performance on a new task in terms of complexity and fluency, but not accuracy, in spoken language.

\subsection{Interventional ILP Studies}

Research on ILP has demonstrated that different aspects of L2 pragmatics are amenable to instruction (Kasper, 1997; Rose, 2005) and that instruction is more effective than simple exposure (Taguchi, 2015). Moreover, there are studies investigating the effects of different instructional methods on ILP development. These instructional studies may roughly fall into three categories: explicit and implicit instruction, input-based and output-based instruction, and task-based instruction.

Regarding the first category, the majority of ILP studies support the advantage of explicit instruction over implicit teaching (Taguchi, 2015). For instance, House (1996) examined the effects of explicit and implicit instruction on advanced German EFL students' pragmatic fluency. House found that both the explicit and implicit group benefited from instruction. However, the explicit group used a higher variety of discourse markers and strategies in role plays. Furthermore, Similarly, Tateyama (2001) compared the efficacy of explicit and implicit instruction in teaching L2 Japanese pragmatic routines to beginning learners. The results showed no significant difference between the two instructional conditions. However, he maintained that factors like motivation and the degree of contact with Japanese speakers may have intervened.

In another study, Martinez-Flor and Fukuya (2005) examined the effects of instruction on learners' production of suggestions in English. An explicit group received metapragmatic information, an implicit group was exposed to pragmalinguistic input enhancement and recast activities, and a control group did not receive equivalent instruction. The results indicated that both explicit and implicit instructional approaches improved learners' production of English suggestions. 
Moreover, Ghobadi and Fahim (2009) compared the effects of explicit and implicit instruction on learning English thanking formulas among intermediate EFL learners. They applied a DCT and role plays as pragmatic measures. The results indicated that explicit instruction was more effective than implicit instruction.

Furthermore, Rose and Ng Kwai-fun (2001) compared the effects of deductive and inductive instruction on compliment and compliment responses. Three intact classes of university students were assigned to one of the three groups (two experimental groups and one control group). The deductive group received film segments and metapragmatic information and the inductive group received the same instruction with no metapragmatic information. The results revealed that both instructional conditions improved pragmatic proficiency. However, deductive instruction was more effective. As Rose (2005) argues, although Rose and Ng Kwai-fun use the terms 'inductive' and 'deductive' to characterize their instructional treatments, the distinguishing characteristics of the treatments is essentially the same as in other studies focusing on implicit versus explicit instructional methods " - the provision (or lack) of explicit metapragmatic information" (p. 394).

Regarding the second category (i.e., input-based and output-based instruction), Takimoto (2009) examined the effectiveness of three types of input-based tasks (i.e., structured input tasks with and without explicit information and problem solving tasks) in teaching English polite request forms to Japanese learners of English. The tasks were repeated to make the input enhancement more effective. The results revealed that the three treatment groups significantly outperformed the control group on a discourse completion test, a listening test, and an acceptability judgment test.

Furthermore, Ahmadi et al. (2011) compared the effects of dictogloss, as an output-based task, with the effects of consciousness raising, as an input-based task, on Iranian EFL learners' acquisition of English request forms. The findings revealed that both treatment conditions significantly improved the participants' 
performance in the immediate and delayed posttests. However, no significant difference was found between the effects of the two conditions.

Moreover, S. Li (2012) explored the impact of input-based practice on developing accurate and speedy requests in L2 Chinese. Thirty intermediate-level learners were assigned to an intensive training group (IT), a regular training group (RT), and a control group. The IT and the RT groups practiced using Chinese request forms through computerized structured input activities. The IT group practiced using the request forms twice as much as the RT group. However, the control group received no practice of the request forms. The results revealed that the input-based practice led to the improvement of accuracy in an oral discourse completion task and to the enhancement of speed in a pragmatic listening judgment task.

In addition, Tajeddin and Bagherkazemi (2014) examined the effects of individual and collaborative output on 54 intermediate Iranian EFL learners' speech act production. There was no control group. They concluded that both types of output had significant effects on the learners' short-term and long-term production of speech acts. Moreover, collaborative output was found to be more effective than individual output.

Concerning the third category (i.e., Task-based Instruction), Tajeddin et al. (2012) investigated the impact of TBLT on Iranian intermediate EFL learners' speech act production, metapragmatic awareness, and pragmatic self-assessment. Seventy five intermediate level EFL students were randomly assigned to three groups: two experimental groups and one control group. The participants in the first experimental group were provided with pragmatic focus on speech acts in pretask and post-task phases. The participants in the second experimental group only received pragmalinguistic and sociopragmatic feedback and scaffolding during task completion. However, the participants in the control group were not exposed to any sort of pragmatic focus. They found that all the three groups had improvements in their speech act production without any significant difference between them. However, metapragmatic awareness and pragmatic self-assessment were improved only in the two experimental groups. 
Moreover, Takimoto (2012) investigated the effects of task repetition on EFL learners' acquisition of request forms. He applied input processing tasks and compared two task repetition conditions, namely identical task repetition and task type repetition. The results revealed that the two treatment groups outperformed the control group and the identical task repetition condition demonstrated statistically more significant improvement in a written discourse completion test and an acceptability judgment test.

Furthermore, Sydorenko (2015) investigated the effects of oral practice through computer-delivered structured tasks (CASTs) with native speaker models and open-ended tasks without native speaker input (i.e., learner-leaner role-plays) on ESL learners' pragmatic development. Two conditions were created in this study: (1) one group of learners practiced request speech acts via CASTs and (2) another group practiced through learner-learner open role-plays. Qualitative analysis of participants' output during practice revealed that rehearsal via CASTs promotes FonF and incorporation of native speaker models into learners' speech while practicing through role-plays leads to more creative, but often pragmatically inappropriate, language and content.

Finally, Kim and Taguchi (2015) studied the effect of task complexity on learning request expressions. Task complexity was operationalized as [+/reasoning]. Seventy three Korean junior high school students were divided into three groups (simple, complex, and control). Both treatment groups performed a pretest, two collaborative tasks, and two posttests, whereas the control group took only the pretest and the posttests. Participants' oral interaction during tasks was audiorecorded and analyzed by the number of pragmatic-related episodes (PREs). The results of a DCT revealed that task complexity levels influenced the occurrence of PREs, but the results revealed no difference in the quality of task outcome between the treatment groups. However, both treatment groups outperformed the control group.

To sum it up, there has been a rapid expansion of ILP interventional studies in the last two decades. The studies have drawn on "common SLA frameworks of 
noticing and explicit/implicit instruction, input processing, and skill acquisition and practice" (Taguchi, 2011). Despite the abundance of interventional studies in L2 pragmatics, the potential effect of task repetition on ILP development is not adequately investigated. In this respect, as noted above, Takimoto (2009) provided some evidence for the effects of input-based task-type repetition on L2 learners' acquisition of English request forms. Furthermore, applying problem solving tasks, Takimoto (2012) examined the effects of identical task repetition and the same task-type repetition on L2 pragmatic development.

To date, no studies have examined the effectiveness of different output-based task repetition conditions, as operationalized in this study, on EFL learners' production of speech acts. Therefore, the present study was designed to investigate the effect of output-based task repetition on EFL learners' ability to produce the speech acts of thanking, apologizing, and refusing. As stated above, three outputbased task repetition conditions were created (ETR, ITR, and NTR). Based on the purpose of the study, the following research question was formulated:

Do different task repetition conditions (ETR, ITR, and NTR) have differential effects on EFL learners' speech act production?

\section{Method}

\subsection{Participants}

The present study involved native speakers of British English and EFL learners as participants. The participants were all either university students or university graduates. Ten native speakers of British English (seven males and three females, age range 23-35) and ten EFL learners (4 males and 6 females, age range 24-35) contributed to the construction of a WDCT. Nine native speakers of British English (six males and three females) were recruited to complete the WDCT to examine its content validity. Their age ranged from 24 to 83 . Three intact classes of English-major students $(\mathrm{n}=80)$ sat the Oxford Placement Test (OPT, Allen, 2004). The ages of the learners ranged from 19 to 34 . None of them had the experience of staying in an English-speaking country. Twenty-three of them reported experience 
of learning English in language institutes. The participants formed three groups. Group 1 was randomly assigned to the ETR condition $(n=26)$, group 2 was assigned to the ITR condition ( $\mathrm{n}=28)$, and group 3 was assigned to NTR condition $(n=26)$. ANOVA results indicated that the three groups were homogeneous in terms of EFL proficiency as determined by their OPT mean scores, $F(2,77)=$ $.771, p=.466$.

\subsection{Instruments}

Two instruments were utilized in the present study: the Oxford Placement Test and a Written Discourse Completion Test (WDCT).

Oxford Placement Test: The OPT consists of listening and grammar sections and includes 100 items in each section. As Allen (2004) maintains, this test has been calibrated against the levels system provided by the Common European Framework of Reference for Languages (CEF), major international language examinations such as IELTS, TOEFL, and TOEIC, and the Cambridge ESOL Examinations. As to the validity of the OPT, Birjandi and Siyyari (2010) found a very high correlation between the scores of the participants in the OPT and their scores in a paper-based TOEFL.

Written discourse completion test: In order to construct the WDCT, the researchers prepared a pool of 36 scenarios (12 scenarios for each speech act). Some were taken from the literature (Bardovi-Harlig, 2009; Bataineh \& Bataineh, 2006; Beebe, Takahashi, \& Uliss-Weltz, 1990; Blum-Kulka \& Olshtain, 1984; Cheng, 2005; Eisenstein \& Bodman, 1986) and some were constructed by the researchers themselves. The prepared scenarios were subjected to situation likelihood investigation and metapragmatic assessment. This instrumentation procedure was carried out among 20 participants (10 EFL learners and 10 native speakers of British English). Following Q. Li (2012), for the EFL learners, the scenarios were 
described in their native language to ensure the lower level learners' comprehension. In the situation likelihood investigation, the 20 participants were asked to indicate on a 5-point scale the likelihood that the scenarios would occur in their daily life, with 1 being the least likely and 5 the most likely. The seven scenarios with the highest likelihood of occurrence were selected for each speech act, and a 21-item WDCT was constructed.

In the metapragmatic assessment, the 20 participants were asked to indicate the power relationship and the social distance between the speaker and hearer in the scenarios and the severity of the situation on a scale of 1 to 5 . As to the social variables of distance and severity, if the mean for the social variable was below 2.5 , it was assigned a - value, if the mean was above 2.5 , it was assigned a + value, and if the mean was equal to 2.5 , the scenario was discarded. With respect to the social variable of power, three values $(-,+$, and $=$ ) were used as follows: If mean < 3 , then the value was - . If mean $\geq 4$, then the value was + , and if the $3 \leq$ mean $<4$, then the value was $=$. The results of the metapragmatic assessment indicated that the scenarios represented various combinations of the three social variables of power, distance, and imposition / severity, as introduced by Brown and Levinson (1987). Table 1 presents the combinations of the social variables and their valuesas determined in metapragmatic assessment-for the scenarios related to each of the three speech acts. The format of Table 1 is adapted from Q. Li (2012).

Table 1

Distribution of social variables across the seven scenarios for each speech act (Based on metapragmatic assessment)

\begin{tabular}{|c|c|c|c|c|c|c|c|c|c|c|c|c|c|c|c|c|c|c|c|c|c|}
\hline \multirow{3}{*}{$\begin{array}{l}\mathbf{S} \\
\mathbf{V}\end{array}$} & \multicolumn{21}{|c|}{ Scenario number and values of social variables } \\
\hline & \multicolumn{7}{|c|}{ Thanking scenarios } & \multicolumn{7}{|c|}{ Apologizing scenarios } & \multicolumn{7}{|c|}{ Refusing scenarios } \\
\hline & 1 & 2 & 3 & 4 & 5 & 6 & 7 & 1 & 2 & 3 & 4 & 5 & 6 & 7 & 1 & 2 & 3 & 4 & 5 & & 7 \\
\hline$P$ & $=$ & + & - & - & $=$ & $=$ & $=$ & + & + & - & - & - & & $=$ & + & $=$ & - & - & $=$ & $=$ & $=$ \\
\hline $\mathrm{D}$ & - & + & - & + & + & - & + & - & + & + & - & + & + & - & - & _ & - & + & + & - & + \\
\hline S & - & - & - & - & + & - & - & + & - & + & - & - & + & - & + & _ & - & & + & - & - \\
\hline
\end{tabular}


Note. $\mathrm{SV}=$ social variable, $\mathrm{P}=$ power, $\mathrm{D}=$ distance, $\mathrm{S}=$ severity

$=$ means the speaker and the hearer are of equal status.

+ means the hearer has higher status $(\mathrm{P})$, the hearer and the speaker are familiar with each other $(\mathrm{D})$, and the situation is severe $(\mathrm{S})$.

- means the speaker has higher status $(\mathrm{P})$, the hearer and the speaker are not familiar with each other (D), and the situation is not severe (S).

The constructed WDCT was reviewed and revised by a native speaker of British English. To ensure the content validity of the WDCT, the researchers piloted it with another group of native speakers of British English $(n=9)$. The results from the native speakers of English indicated that the scenarios in the WDCT elicited the intended speech acts. Then, the WDCT was administered to the participants as the pretest. It took about 40 minutes to complete. The participants' responses were rated based on a 6-point rating scale developed by Taguchi (2006). Based on this rating scale, each response received a score from 0 to 5. This scale takes three aspects of speech act production into consideration: contextual appropriateness, grammatical accuracy, and discoursal felicity.

Regarding the inter-rater reliability of scoring, 30 participants' pretest papers were rated by one of the researchers and a native speaker teacher of British English. There was a very high correlation coefficient of .92 between the two sets of scores. Concerning the internal consistency reliability of the WDCT, the analysis of 40 participants' pretest scores revealed a Cronbach's coefficient Alpha value of .90 indicating very good internal consistency reliability.

\subsection{Instructional Process}

\subsubsection{Materials}

In this study, the participants engaged in collaborative text creation activities (Ellis, 1997) of writing English conversations and English letters. Eight conversations and two letters were prepared for each of the three speech acts of thanking, apologizing, and refusing. Most of the conversations and letters were adopted and 
adapted from various textbooks (Craven, Thaine, \& Logan, 2008; Dignen, Flinder, \& Sweeney, 2004; Hancock \& McDonald, 2009a; Hancock \& McDonald, 2009b; Oxenden \& Latham-Koenig, 2006; Swan \& Walter, 1993) and internet sources (Koltia, 2013; Savetz Publishing, 2010a; Savetz Publishing, 2010b). Some of them were constructed by the researchers themselves.

Each conversation or letter comprised 4-7 turns or sentences. These instructional materials included the pragmatic strategies and expressions associated with the three speech acts. The conversations and letters appeared in two formats. The ETR group received the plain format, printed in 14-point Times New Roman font, and the ITR group received the visually enhanced format, but the NTR group received neither of them. The visually enhanced input was designed to draw the learners' attention to the pragmatic strategies and expressions associated with the given speech acts. In the visually enhanced format, the conversations and letters were printed in 14-point Times New Roman font and the instances of the speech acts (including the head acts and adjuncts) were bolded and underlined. For example:

David: Martin, I wonder if you could do me a favor.

Martin: Sure. What do you need?

David: My car's at the repair shop and I need to pick it up at 3:00 o'clock. Do you think you could give me a lift?

Martin: Oh. I'd like to, but I have a doctor's appointment at that time.

David: That's OK. I understand.

Martin: Maybe you could get Jack to take you.

David: Good idea. 
Then, a scenario was constructed based on each conversation or letter (henceforth text). For instance, the scenario constructed based on the above conversation was as follows:

Scenario: David's car is at the repair shop and he needs to pick it up at 3:00 o'clock. He asks Martin to give him a lift, but Martin has an appointment with his doctor at that time and refuses David's request.

\subsubsection{Treatment}

Each instructional session started with a whole-class discussion (approximately 5 minutes) about the learners' real-life experiences of the speech act which was to be practiced in that session. Then, the prepared texts and scenarios were used in the instructional groups based on a four-step procedure as follows:

Step A (approximately 6 minutes): In the ETR, ITR, and NTR groups, a scenario was presented to the participants. The participants were paired up and asked to write collaboratively a four-to-seven-turn conversation or four-to-seven-sentence letter in English based on the scenario presented to them. The learners were given an answer sheet and were asked to write their text on it. The teacher monitored the class to ensure that the learners understood the scenarios correctly and provided the learners with any help they required about lexico-grammatical aspects, but not pragmalinguistic and sociopragmatic aspects. The instructions, grammar explanations, and meanings of the new words were presented in Persian to ensure the learners' comprehension.

Step B (approximately 5 minutes): After the participants constructed their text in pairs, the learners in the ETR group received the plain format of the original text and the learners in the ITR group received the visually enhanced format. However, the learners in the NTR group did not receive the original text at all. Then, the 
original texts were read aloud and explained by the teacher. In the ETR group, the lexico-grammatical aspects were explained at first. Then, contextual clues were used to explain the pragmalinguistic and sociopragmatic aspects of the speech acts in the text with an emphasis on how the social variables of power, distance, and severity influenced the choice of speech act strategies and expressions. However, in the ITR group, the participants received explanations only about the lexicogrammatical aspects of the text and there was no metapragmatic explanation. Instead, the participants were required to read the visually enhanced text and discuss, with their partner, how appropriately the given speech act was materialized (i.e., a CR task). The purpose was to raise the learners' awareness of pragmatic strategies and the realization of the given speech act in the given context. The participants in the NTR group were instructed to change their partners and discuss the vocabulary and grammatical aspects of their text with their new partner. The purpose was for the NTR group's learners to spend the time on lexical and grammatical aspects when working with their new partners. The teacher monitored the learners to ensure that there was no discussion of pragmatic aspects.

Step C (approximately 4 minutes): Then, in the ETR and ITR groups, the learners engaged in a form-comparison activity. They were required to compare their own text with the plain format and the visually enhanced format of the original text respectively and discover the differences between the two texts. The learners were not allowed to make changes to their output, take notes, or copy the original text. In the NTR group, the learners went back to their first partners and were required to reflect on their own output and talk about whether and how they could improve it. The teacher monitored the learners and answered any questions the learners had about the lexico-grammatical aspects. The learners were not allowed to make changes to their output at this stage or to take notes about their metatalk.

Step D (approximately 4 minutes): The texts produced by the participants in all the three groups as well as the plain format and the visually enhanced format of the original text, which had been given to the ETR group and ITR group respectively, were collected by the teacher. Then, the participants in the three groups were 
required to construct another text about the same scenario, with making any changes they preferred. The learners wrote down their text on another answer sheet. While the learners were regenerating the text, the teacher monitored the learners and provided help and feedback only about lexico-grammatical aspects. The teacher provided no help or feedback about pragmalinguistic and sociopragmatic aspects.

\subsection{Procedure}

Three classes of English-major students took part in the experimental phase of this study. Before the treatment, the OPT was administered to the three classes to check their homogeneity in terms of EFL proficiency. As noted above, the result of oneway between-groups ANOVA revealed no significant difference between the OPT mean scores of these three groups, which indicated the homogeneity of these groups in terms of EFL proficiency level. The first group $(\mathrm{n}=26)$ was randomly assigned to the ETR condition, the second group $(n=28)$ was randomly assigned to the ITR condition, and the third group $(n=26)$ was assigned to the NTR group. Then, the WDCT was administered to the participants in all the three groups as the pretest and it took about 40 minutes to complete.

Then, the three groups received instruction on the speech acts. The instructional treatments were implemented for six sessions, each lasting about 90 minutes. Two sessions were devoted to the instruction of each of the speech acts of thanking (sessions 1 and 2), apologizing (sessions 3 and 4), and refusing (sessions 5 and 6). Since the type of the speech act (i.e., thanking, apologizing, and refusing) was not an independent variable in this study, the order in which the three speech acts were presented did not matter.

The instruction for all the three groups was carried out in Persian and in accordance with the treatment conditions designed for each of the groups. All the three classes were taught by the first author of this study who was also the instructor of most of the participants at university. After the instruction was 
completed, the WDCT was administered to the participants as the posttest two or three days after the last instructional treatment session.

\section{Results}

To compare the performance of the three groups on the WDCT pretest, a one-way between-groups ANOVA was performed. Table 2 presents the descriptive statistics of the performance of the three groups on the WDCT pretest and posttest. Table 2 indicates that, in the WDCT pretest, the NTR group $(M=68.58)$ had the best performance, the ITR group ( $\mathrm{M}=66.39)$ came second, and the ETR group $(\mathrm{M}=$ 62.69) had the weakest performance.

Table 2

Descriptive statistics for the WDCT pretest and posttest scores

\begin{tabular}{llllll}
\hline Test & Group & N & Mean & $\begin{array}{l}\text { Std. } \\
\text { Deviation }\end{array}$ & Std. Error \\
\hline Pretest & ETR & 26 & 62.69 & 13.466 & 2.64 \\
& ITR & 28 & 66.39 & 11.80 & 2.23 \\
& NTR & 26 & 68.58 & 11.31 & 2.22 \\
& Total & 80 & 65.90 & 12.30 & 1.37 \\
Posttest & ETR & 26 & 80.54 & 10.85 & 2.13 \\
& ITR & 28 & 73.14 & 11.47 & 2.17 \\
& NTR & 26 & 67.88 & 10.66 & 2.09 \\
& Total & 80 & 73.84 & 12.03 & 1.34 \\
\hline
\end{tabular}

Note. ETR $=$ explicit task-repetition group, ITR = implicit task-repetition group, NTR $=$ no-input task-repetition group

Levene's test indicated that the assumption of homogeneity of variances was met in the pretest, $F=.035, p=.966$. The ANOVA results (see Table 3 ) revealed that there was no statistically significant difference at the $p<.05$ level in the pretest scores for the three groups, and the effect size, calculated using eta squared, was 
.04 . This suggests that the three groups were homogeneous in terms of speech act production ability at the outset of the study.

Table 3

ANOVA results for the performance of the three groups on the WDCT pretest

\begin{tabular}{llllll}
\hline & $\boldsymbol{S S}$ & $\boldsymbol{d} \boldsymbol{f}$ & $\boldsymbol{M S}$ & $\boldsymbol{F}$ & $\boldsymbol{p}$ \\
\hline Between Groups & 460.64 & 2 & 230.32 & 1.54 & .220 \\
Within Groups & 11492.56 & 77 & 149.25 & & \\
Total & 11953.20 & 79 & & & \\
\hline
\end{tabular}

Then, the learner' performance was examined in terms of differences across the two administration of the WDCT. The purpose was to see if there were any statistically significant changes in the learners' performance from the pretest to the posttest. As demonstrated in Table 2, the performance of the ETR group improved from the pretest $(M=62.69)$ to the posttest $(M=80.54)$. Similarly, there was an increase in the mean score of the ITR group from the pretest $(M=66.39)$ to the posttest $(M=73.14)$, whereas the mean score of the NTR group decreased from the pretest $(M=68.58)$ to the posttest $(M=67.88)$.

Paired sample t-test results revealed that the ETR group made a statistically significant gain from the pretest to the post test, and the effect size, calculated using eta squared, was .59. Similarly, in the ITR group, the increase in the mean score from the pretest to the posttest was statistically significant, and the effect size was .32. However, in the NTR group, the change from the pretest to the posttest was not statistically significant, and the effect size was .03 . Table 4 presents the results of the t-test analysis. Thus, it appears that the ETR and ITR instructional conditions worked successfully in teaching speech acts to the EFL learners, whereas the NTR condition did not lead to a statistically significant change in the learners' performance. 
Table 4

Results of paired samples t-test for the three groups on pretest and posttest

\begin{tabular}{|c|c|c|c|c|c|c|}
\hline Groups & Mean & $\begin{array}{l}\text { Std. } \\
\text { Deviation }\end{array}$ & $\begin{array}{l}\text { Std. } \\
\text { Error } \\
\text { Mean }\end{array}$ & $T$ & $d f$ & $\begin{array}{l}P \\
\text { tailed })\end{array}$ \\
\hline $\begin{array}{ll}\text { ETR } & \text { (PRT- } \\
\text { PST) } & \end{array}$ & -17.85 & 11.62 & 2.28 & -7.834 & 25 & .000 \\
\hline $\begin{array}{l}\text { ITR } \\
\text { PST) }\end{array}$ & -6.75 & 7.59 & 1.43 & -4.706 & 27 & .000 \\
\hline $\begin{array}{l}\text { NTR (PRT- } \\
\text { PST) }\end{array}$ & .69 & 2.36 & .463 & 1.494 & 25 & .148 \\
\hline
\end{tabular}

Note. ETR $=$ explicit task repetition group, ITR $=$ implicit task repetition group, $\mathrm{NTR}=$ no-input task repetition group, $\mathrm{PRT}=$ pretest, $\mathrm{PST}=$ posttest

To determine whether the three groups of learners had differences in their ability to produce the speech acts after the treatment, the data collected through the posttest was subjected to one-way between-groups ANOVA. It should be noted that ANCOVA, using the pretest scores as the covariate, was avoided as the assumption of homogeneity of regression slopes was found to be violated.

Levene's test revealed that the assumption of homogeneity of variances was met in the posttest, $F=.148, p=.863$. The ANOVA results (see Table 5) indicated that there was a statistically significant difference at the $\mathrm{p}<.05$ level in the posttest scores for the three groups, and the effect size, calculated using eta squared, was .18 .

Table 5

ANOVA results for the WDCT posttest scores

\begin{tabular}{llllll}
\hline & $\boldsymbol{S S}$ & $\boldsymbol{d} \boldsymbol{f}$ & $\boldsymbol{M S}$ & $\boldsymbol{F}$ & $\boldsymbol{p}$ \\
\hline Between & 2102.34 & 2 & 1051.17 & 8.67 & .000 \\
Groups & 9338.54 & 77 & 121.28 & & \\
Within Groups & 11440.89 & 79 & & & \\
Total & & & & \\
\hline
\end{tabular}


Post hoc comparisons, using Tukey HSD test, was performed to determine which pair(s) of the three posttest means differed significantly. As demonstrated in Table 6, the results of Tukey HSD test revealed that the ETR group performed significantly better than the ITR and the NTR groups. However, there was no statistically significant difference between the ITR and NTR groups.

Table 6

Multiple comparisons of the three groups on the WDCT posttest

\begin{tabular}{lllll}
\hline & & $\begin{array}{l}\text { Mean } \\
\text { Difference }\end{array}$ & $(\mathbf{I}-$ & \\
(I) Groups & (J) Groups & J) & Std. Error & $\boldsymbol{p}$ \\
\hline \multirow{2}{*}{ ETR } & ITR & 7.40 & 2.99 & .042 \\
& NTR & 12.65 & 3.05 & .000 \\
ITR & ETR & -7.40 & 2.99 & .042 \\
& NTR & 5.26 & 2.99 & .192 \\
\multirow{2}{*}{ NTR } & ITR & -5.26 & 2.99 & .192 \\
& ETR & -12.65 & 3.05 & .000 \\
\hline
\end{tabular}

Note. ETR $=$ explicit task-repetition group, ITR $=$ implicit task-repetition group, NTR $=$ no-input task-repetition group

These results lead to the following answer to the research question of 'Do different task repetition conditions (ETR, ITR, and NTR) have differential effects on EFL learners' speech act production?' The answer is confirmative. The ETR, ITR, and NTR conditions have differential effects on EFL learners' speech act production. 


\section{Discussion}

The present study investigated the effects of output-based task repetition accompanied by input plus metapragmatic information, visually enhanced input plus CR, and no input on EFL learners' speech act production. The results demonstrated that the performance of ETR and ITR groups, but not that of the NTR group, significantly improved from the pretest to the posttests. Furthermore, the ETR condition was found to be significantly more effective than the ITR and NTR conditions in enhancing the learners' speech act production ability.

The first point to discuss is the potential utility of task repetition in L2 (pragmatics) instruction. The results of the present study are compatible with the findings of previous studies on task repetition (e.g., Ahmadian, 2011; Bygate \& Samuda, 2005), which concluded that repetitions of the same task can facilitate learners' L2 performance and acquisition. In this regard, Takimoto (2012), drawing on problem solving tasks, also concluded that identical task repetition and task type repetition groups outperformed the control group in his study. It needs to be noted that Takimoto focused on the effects of input processing task repetition. However, the present study demonstrated that output production task repetition can be an effective instructional technique in L2 speech act instruction if it is accompanied by input coupled with metapragmatic information or visually enhanced input coupled with CR. This is in line with Sheppard's (2006) finding that output generation task repetition can promote L2 development if it is accompanied by input or feedback.

The second point to be noted is the role of output. The type of the task utilized in this study involved output generation by the learners. In order for effective learning to take place, learners need to use the newly received language in their own production. As Bygate and Samuda (2005) rightly argue "a common learning and teaching problem is to get learners to integrate knowledge that is available to them into their active language use" (p. 270). The output generation tasks used in this study provided a chance for the learners to apply their previously known pragmatic knowledge in their language production. Furthermore, after their first performance of output-generation tasks, the learners in the ETR and ITR conditions 
were exposed to pragmatic aspects of language through input coupled with metapragmatic information and input coupled with visual enhancement and CR respectively. The second performance of the task provided an opportunity for the learners to practice using this new pragmatic knowledge. It is likely that the integration of the pragmalinguistic and sociopragmatic knowledge into the second performance of the task significantly contributed to the learners' pragmatic development.

Furthermore, the effectiveness of output generation tasks used in this study can be explained in terms of output hypothesis and the three functions of output (Swain, 1995; Swain \& Lapkin, 1995): (1) the output may have caused the learners to notice the gaps in their own pragmatic knowledge, (2) their first output may have enabled the learners to produce pragmatic hypotheses and test them against the input they received before the second performance of the task. It needs to be noted that this type of hypothesis testing could not take place in the NTR groups as this group did not receive any pragmatic input after the first performance of the task, and (3) the third function that Swain refers to is the use of metalanguage. In the present study, the learners in the ETR, ITR, and NTR groups engaged in metapragmatic discussion before the second performance of the task.

The last point of concern is the efficacy of explicit versus implicit pragmatic instruction, which applies to the ETR and ITR groups. The pragmalinguistic and sociopragmatic information presented to the ETR group was more explicit than that provided for the ITR group. The results revealed a statistically significant gain in speech act production by both groups from the pretest to the posttest. However, no statistically significant change was observed in mean score of the NTR group from the pretest to the posttest. This suggests that output-based task repetition accompanied by implicit or explicit instruction is effective.

Provision of metapragmatic information is the key factor that distinguishes between the implicit and explicit instruction. However, explicit instruction often involves more than just metapragmatic explanation and includes activities such as video viewing, dialogue analysis, and cross-linguistic comparisons. There are also 
different operationalizations of implicit instruction across studies. Some studies simply use input exposure, while others use input enhancement or consciousnessraising tasks (Taguchi, 2015).

Rose and Ng Kwai-fun (2001) argue that inductive instruction and guided discovery can result in more confusion than comprehension. However, the results of the present study revealed that the ITR condition, in contrast to the NTR condition, significantly led to L2 pragmatic development from the pretest to the posttest. This may be accounted for by the operationalization of implicit instruction (i.e., learners' exposure to visually enhanced input and their engagement in CR tasks) and the output-based task repetition that the learners engaged in. In other words, the improvement in the ITR group may be attributed to the joint effects of output production, visual enhancement, and CR activities the learners engaged in.

The learners' first output production may have caused them to notice what Doughty and Williams (1998) call "holes" in their interlanguage. In other words, the learners' creation of the first text may have led to the learners' awareness of the pragmatic deficiencies in their L2 pragmatic competence. It is likely that this kind of noticing stimulated the ITR groups' learners to focus on certain pragmatic aspects in the input presented to them after the first performance of the task. This may have enabled them to notice the pragmatic gaps between the second language and their interlanguage. As Swain (1998) puts it, noticing a gap between the target language and the interlanguage may be stimulated by noticing a hole in the output. Moreover, based on the role of practice in cognitive skill acquisition (Ericsson \& Charness, 1994), it may be argued that the second performance of the task created a chance for the learners to reinforce their mastery over the newly acquired pragmatic strategies and expressions. Thus, the conclusion may follow that visual enhancement and CR activities were not the only factors contributing to the development of the learners' speech act production ability in the implicit group.

The present study also revealed the advantage of the ETR group over the ITR group. This is in line with the findings of the majority of previous studies that showed the superiority of explicit teaching over implicit L2 pragmatics instruction (Rose \& Kasper, 2001a; Rose, 2005). Taguchi (2015) found that explicit formfocused instruction involving metapragmatic information was generally more 
effective than its implicit counterpart even when the input is made salient through enhancement techniques. Similarly, the results of the present study showed that even when implicit and explicit instructional approaches are integrated into outputbased task repetition activities, the implicit method is not as effective as its implicit counterpart. Although the ETR group differed from the ITR group in that only the ETR group was provided with metapragmatic information, the superiority of the ETR group over the ITR group may be attributed to the combination of the features associated with the ETR condition rather than metapragmatic information on its own. The provision of metapragmatic information, exposure to the plain format of texts, form-comparison, and output-production task repetition, altogether, might have led to the learners' awareness of the speech act features. In other words, the combination of these factors may have enabled the learners in ETR group to accomplish form-function-context mappings and internalize the associated pragmatic knowledge more effectively than the ITR group.

\section{Conclusion}

This study aimed to investigate the effects of output-based task repetition on EFL learners' speech act production. The results not only confirm the teachability of speech act features, but also indicate the utility of output-based task repetition in L2 speech act instruction. The results revealed that output- based task repetition can be effective if it is accompanied by input plus metapragmatic information or visually enhanced input plus CR tasks. In other words, repetition of output generation tasks accompanied by only learners' reflection and metatalk, without exposing the learners to any input, seems not to be effective in enhancing learners' speech act production ability.

Furthermore, there was the question of whether output-based task repetition accompanied by implicit instruction could be as effective as output-based task repetition accompanied by implicit instruction. The results indicated that outputbased task repetition could improve the learners' speech act production ability 
when there was explicit instruction more than when there was implicit instruction before the second performance of the task. In line with past research, these findings reveal the significant role of pragmatic input and output in English language teaching. The results also indicate the primacy of explicit instruction over implicit instruction when input is coupled with output-based task repetition activities.

As Taguchi (2015) argues, implicit approaches to L2 pragmatics instruction can be just as effective as explicit teaching provided that they draw learners' attention to form-function-context mappings. In the output-based task repetition activities utilized in this study, a set of factors seemed to draw the learners' attention to form-function-context mappings. The learners received scenarios based on which they were required to construct texts. Furthermore, they engaged in CR tasks and they were given the chance to compare and contrast their own output with the visually enhanced text including the target pragmatic features. The scenarios, output, visually enhanced input, CR and form-comparison activities were expected to increase the salience of the pragmatic aspects of the input the learners received in the ITR group and to make implicit instruction as effective as explicit teaching. Even with such factors utilized to enhance the salience of the pragmatic features in the input and to promote form-function-context mappings, implicit instruction did not work as effectively as explicit teaching.

At least, three limitations of this study need to be pointed out. First, this study followed a comparison group design, which involves no control group and aims to compare two or more groups receiving different treatments (Mackey \& Gass, 2005). Further studies including a control group can allow us "to assess whether post-treatment effects observed in the experimental group(s) are in fact the result of the treatment" (Rose \& Kasper, 2001b, p. 57). Second, the WDCT data provided insight into what the participants knew rather than what they could do in real-life conditions. Further studies drawing on naturalistic data can delve into what learners can do in real life. Third, the present study merely focused on learners' accuracy and appropriacy in the production of speech acts. Further research is required to investigate the effects of task repetition on fluency in the production of speech acts. 


\section{References}

Ahmadi, A., Ghafar Samar, R., \& Yazdanimoghaddam, M. (2011). Teaching requestive downgraders in L2: How effective are input-based and output-based tasks? Iranian Journal of Applied Linguistics (IJAL), 1 (2), 1-30.

Ahmadian, M. J. (2011). The effect of 'massed' task repetitions on complexity, accuracy and fluency: Does it transfer to a new task? The Language Learning Journal, 39 (3), 269-280.

Allen, D. (2004). Oxford placement test 1. Oxford: Oxford University Press.

Bardovi-Harlig, K. (2009). Conventional expressions as a pragmalinguistic resource: Recognition and production of conventional expressions in L2 pragmatics. Language Learning, 59 (4), 755-795.

Bataineh, R. F., \& Bataineh, R. F. (2006). Apology strategies of Jordanian EFL university students. Journal of Pragmatics, 38, 1901-1927.

Beebe, L., Takahashi, T., \& Uliss-Weltz, R. (1990). Pragmatic transfer in ESL refusals. In R. Scacella, E. Anderson, \& S. Krashen (Eds.), Developing communication competence in a second language (pp. 55-73). New York: Newbury House.

Birjandi, P., \& Siyyari, M. (2010). Self-assessment and peer-assessment: A comparative study of their effects on writing performance and rating accuracy. Iranian Journal of Applied Linguistics, 13 (1), 23-45.

Blum-Kulka, S., \& Olshtain, E. (1984). Request and apologies: A crosscultural study of speech act realization patterns. Applied Linguistics, 5 (3), 196-213.

Brown, P., \& Levinson, S. (1987). Politeness: Some universals in language use. Cambridge: Cambridge University Press.

Bygate, M. (1996). Effect of task repetition: Appraising the development of second language learners. In J. Willis, \& D. Willis (Eds.), Challenge and change in language teaching (pp. 136-146). Oxford: Heinemann. 
Bygate, M. (2001). Effects of task repetition on the structure and control of oral language. In M. Bygate, P. Skehan, \& M. Swain (Eds.), Researching pedagogic tasks: Second language learning, teaching and testing (pp. 23-48). Harlow: Longman.

Bygate, M., \& Samuda, V. (2005). Integrative planning through the use of task repetition. In R. Ellis (Ed.), Planning and task performance in a second language (pp. 37-74). Amsterdam: John Benjamins.

Cheng, S. W. (2005). An exploratory cross-sectional study of interlanguage pragmatic development of expressions of gratitude by Chinese learners of English. Unpublished PhD dissertation, University of Iowa, USA.

Craven, M., Thaine, C., \& Logan, S. (2008). Cambridge English skills: Real listening and speaking level three. Cambridge: Cambridge University Press.

Dignen, B., Flinder, S., \& Sweeney, S. (2004). English 365: Book two. Cambridge: Cambridge University Press.

Doughty, C., \& Williams, J. (1998). Pedagogical choices in focus on form. In C. Doughty \& J. Williams (Eds.), Focus on form in classroom second language acquisition (pp. 197-261). New York: Cambridge University Press.

Eisenstein, M., \& Bodman, J. W. (1986). "I very appreciate": Expressions of gratitude by native and nonnative speakers of American English. Applied Linguistics, 7 (2), 167-185.

Ellis, R. (1997). SLA research and language teaching. Oxford: Oxford University Press.

Ellis, R. (2005). Planning and task-based performance: Theory and research. In R. Ellis (Ed.), Planning and task performance in a second language (pp. 3-34). Amsterdam: John Benjamins.

Ellis, R. (2009). The differential effects of three types of task planning on the fluency, complexity and accuracy in L2 oral production. Applied Linguistics, 30 (4), 474-509.

Ericsson, K. A., \& Charness, N. (1994). Expert performance: Its structure and acquisition. American Psychologist, 49 (8), 725-747.

Gass, S., Mackey, A., Fernandez, M., \& Alvarez-Torres, M. (1999). The effects of task repetition on linguistic output. Language Learning, 49, 549-580. 
Ghobadi, A., \& Fahim, M. (2009). The effect of explicit teaching of English thanking formulas on Iranian EFL intermediate level students at English language institutes. System, 37, 526-537.

Hancock, M., \& McDonald, A. (2009a). English results: Preintermediate student's book. Oxford: Oxford University Press.

Hancock, M., \& McDonald, A. (2009b). English results: Intermediate student's book. UK: Oxford: Oxford University Press.

House, J. (1996). Developing pragmatic fluency in English as a foreign language: Routines and metapragmatic awareness. Studies in Second Language Acquisition, 18, 225-253.

Jernigan, J. E. (2007). Instruction and developing second language pragmatic competence: An investigation into the efficacy of output (Doctoral dissertation, Florida State University). Available from ProQuest Dissertations and Theses database.

Kasper, G. (1997). Can pragmatic competence be taught? (NetWork \#6) [HTML document]. Honolulu: University of Hawai $i$, Second Language Teaching \& Curriculum Center. Retrieved from http://www.lll.hawaii.edu/nflrc/NetWorks/NW6/

Kim, Y., \& Taguchi, N. (2015). Promoting task-based pragmatics instruction in EFL classroom contexts: The role of task complexity. The Modern Language Journal, 99 (4), 656-677.

Koltia, A. (2013). 112 phrases for saying thank you in any situation. Retrieved from http://www.myenglishteacher.eu/blog/how-to-say-thank-you-26-thank-you-sayings/

Li, Q. (2012). Effects of instruction on adolescent beginners' acquisition of request modification. TESOL Quarterly, 46 (1), 30-55.

$\mathrm{Li}, \mathrm{S}$. (2012). The effects of input-based practice on pragmatic development of requests in L2 Chinese. Language Learning, 62 (2), 403-438.

Lynch, T., \& Maclean, J. (2000). Exploring the benefits of task repetition and recycling for classroom language learning. Language Teaching Research,4, 221- 250 . 
Mackey, A., \& Gass, S. M. (2005). Second language research: Methodology and design. New Jersey: Lawrence Erlbaum Associate.

Martınez-Flor, A., \& Fukuya, Y. J. (2005). The effects of instruction on learners' production of appropriate and accurate suggestions. System, 33, 463-480.

Nemeth, N., \& Kormos, J. (2001). Pragmatic aspects of task-performance: The case of argumentation. Language Teaching Research, 5, 213-240.

Oxenden, C., \& Latham-Koenig, C. (2006). New English file: Intermediate student's book. Oxford: Oxford: Oxford University Press.

Pica, T. (2011).). Second Language acquisition research: Applied and applicable orientations to practical questions and concerns. In E. Hinkel (Ed.), Handbook of research in second language teaching and learning (Vol. 2, pp.257-273). New York: Routledge.

Rose, K. R. (2005). On the effects of instruction in second language pragmatics. System, 33(3), 385-399.

Rose, K. R., \& Kasper, G. (2001a). Pragmatics in language teaching. New York: Cambridge University Press.

Rose, K. R., \& Kasper, G. (2001b). Classroom research on interlanguage pragmatics. In K. R. Rose \& G. Kasper (Eds.), Pragmatics in language teaching (pp. 33-60). Cambridge: Cambridge University Press.

Rose, K. R., \& Ng Kwai-fun, C. (2001). Inductive and deductive teaching of compliments and compliments responses. In K. R. Rose \& G. Kasper (Eds.), Pragmatics in language teaching (pp. 145-170). New York: Cambridge University Press.

Savetz Publishing (2010a). Apology letters. Retrieved from http://www.apologyletters.net/

Savetz Publishing (2010b). Thank you letters. Retrieved from http://www.thankyouletters.ws/

Sheppard, C. (2006). The effects of instruction directed at the gaps second language learners noticed in their oral production. Doctoral Dissertation, University of Auckland, New Zealand.

Swain, M. (1995). Three functions of output in second language learning. In G. Cook \& B. Seidlhofer (Eds.), Principles and practice in applied linguistics: 
Studies in honour of H.G. Widdowson (pp. 125-144). Oxford: Oxford University Press.

Swain, M. (1998). Focus on form through conscious reflection. In C. Doughty \& J.Williams (Eds.), Focus on form in classroom second language acquisition (pp.64-81). New York: Cambridge University Press.

Swain, M., \& Lapkin, S. (1995). Problems in output and the cognitive processes they generate: a step towards second language learning. Applied Linguistics, 16 (3), 371-391.

Swan, M., \& Walter, C. (1993). The new Cambridge English course: Book four. Cambridge: Cambridge University Press.

Sydorenko, T. (2015).The use of computer-delivered structured tasks in pragmatic instruction: An exploratory study. Intercultural Pragmatics. 12 (3), 333-362.

Taguchi, N. (2006). Analysis of appropriateness in a speech act of request in L2 English. Pragmatics, 16 (4), 513-533.

Taguchi, N. (2011). Teaching pragmatics: Trends and issues. Annual Review of Applied Linguistics, 31, 289-310.

Taguchi, N. (2015). Instructed pragmatics at a glance: Where instructional studies were, are, and should be going. Language Teaching, 48, 1-50.

Tajeddin, Z., \& Bagherkazemi, M. (2014). Short-term and long-term impacts of individual and collaborative pragmatic output on speech act production. TELL, 8(1), 39-164.

Tajeddin, Z., Keshavarz, M. H., \& Zand-Moghadam, A. (2012). The effect of taskbased language teaching on EFL Learners' pragmatic production, metapragmatic awareness, and pragmatic self-assessment. Iranian Journal of Applied Linguistics, 15 (2), 139-166.

Takimoto, M. (2009). The Effects of input-based tasks on the development of learners' pragmatic proficiency. Applied Linguistics, 30, 1-25.

Takimoto, M. (2012). Assessing the effects of identical task repetition and tasktype repetition on learners' recognition and production of second language request downgraders. Intercultural Pragmatics, 9 (1), 71-96. 
Tateyama, Y. (2001). Explicit and implicit teaching of pragmatic routines. In K. R. Rose \& G. Kasper (Eds.), Pragmatics in language teaching (pp. 200-222). Cambridge: Cambridge University Press.

Van den Branden, K. (2007). Second language education: Practice in perfect learning conditions? In R. M. DeKeyser (Ed.), Practice in a second language: Perspectives from applied linguistics and cognitive psychology (pp. 161- 179). Cambridge: Cambridge University Press. 


\section{Notes on Contributors:}

Hossein Ahmadi holds BA and MA degrees in English Language Teaching (ELT). $\mathrm{He}$ is currently a Ph.D. candidate of ELT at Science and Research Branch, Islamic Azad University, Tehran, Iran. He has published a number of books and articles related to ELT. His areas of interest currently include EFL reading, EFL writing, sociocultural theory, and interlanguage pragmatics.

Farid Ghaemi is an assistant professor of applied Linguistics at Karaj Branch, Islamic Azad University, Karaj, Iran. He has taught undergraduate and graduate courses for more than twenty years, and published a number of books and articles related to applied linguistics. His main interests are language teaching, first language acquisition, and second language acquisition research.

Parviz Birjandi obtained his Ph.D. in English education from the University of Colorado in Boulder. He is a professor of ELT at Science and research Branch, Islamic Azad University, Tehran, Iran. He has worked as a programmer and materials developer for over 30 years. His areas of interest include first language acquisition, second language acquisition, and testing and assessment. 